\title{
The use of new web technologies for the analysis, preservation, and outreach of paleontological information and its application to La Rioja (Spain) paleontological heritage
}

\author{
José M. Valle Melón, Álvaro Rodríguez Miranda, \\ Félix Pérez-Lorente, and Angélica Torices
}

\begin{abstract}
The present work proposes a project of digital preservation and dissemination of information concerning paleontological sites located in the municipality of Enciso (La Rioja, Spain) by means of the regional SDI (Spatial Data Infrastructure) of La Rioja Government. In its original configuration, the system provides the location and general descriptive data of all the officially declared sites within the municipal boundaries. Besides, in-depth information is provided for one particular case-Valdecevillo site-for which the available datasets generated over the last 30 years (photographs, slides, plans, papers, etc.) were reviewed and sorted. Afterwards, a choice of this material was selected for digitization and online dissemination. Moreover, information has been enriched with a three-dimensional (3D) model of the current state and a video report. The present work concludes with a reflection on the usefulness and the implications of this approach for the management of the paleontological heritage.
\end{abstract}

José M. Valle Melón. Laboratorio de Documentación Geométrica del Patrimonio - Universidad del País Vasco (UPV/EHU), Vitoria-Gasteiz (España).jm.valle@ehu.eus Álvaro Rodríguez Miranda. Laboratorio de Documentación Geométrica del Patrimonio - Universidad del País Vasco (UPV/EHU), Vitoria-Gasteiz (España). alvaro_rodriguez@ehu.eus Félix Pérez-Lorente. Universidad de La Rioja, Logroño (España). felix.perez@ext.unirioja.es Angélica Torices. Cátedra de Paleontología, Universidad de La Rioja, Logroño (España). angelica.torices@unirioja.es

Keywords:palaeontology; ichnite; dinosaur footprint; SDI (Spatial Data Infrastructures); preservation of information

Submission: 23 August 2018 Acceptance: 23 January 2019

Valle Melón, José M., Rodríguez Miranda, Álvaro, Pérez-Lorente, Félix, and Torices, Angélica. 2019. The use of new web technologies for the analysis, preservation, and outreach of paleontological information and its application to La Rioja (Spain) paleontological heritage. Palaeontologia Electronica 22.1.1T 1-10. https://doi.org/10.26879/918 palaeo-electronica.org/content/2019/2422-digital-preservation 


\section{INTRODUCTION}

The Autonomous Community of La Rioja has an exceptional paleontological richness that has received scientific recognition nationally and internationally. Some of its most characteristic features are the numerous sites of dinosaur footprints (Pérez-Lorente, 2017). Examples of community interest in this type of heritage are the existence of numerous marked and protected sites (Figure 1), the creation of interpretation centers, as well as the establishment of cultural routes and even a theme park.

The present work focuses on the recovery of existing information about these sites, especially the information that remains unpublished and/or is difficult to access. The objective is to develop strategies for its free availability, through the Internet, using technologies and standardized formats, making it henceforth interoperable. This objective aims, firstly, to enhance the knowledge and research of this heritage and, secondly, to comply with the requirements of European and Spanish legislation regarding the reuse of information and the dissemination of data.

In the scientific community, there is an interesting debate on whether initiatives to promote the outreach of heritage information are beneficial or counterproductive in terms of the physical preservation of sites. Our general opinion is that they are mostly positive as they increase knowledge about the heritage, make the local population aware of the interest of these places, and involve them in their maintenance, facilitate the management of these resources by the administrations and their use by of other agents for tourism, social purposes etc. All these benefits undoubtedly increase the value of the paleontological heritage and, directly, have an impact on a greater social concern for its physical preservation.

However, it is clear that there will also be cases in which the information must be managed in a more restricted manner, especially if it is considered that there is a high risk of vandalism or anthropogenic degradation, and it is not possible to provide additional measures that could alleviate it.

In this case, all the sites, compiled in the repository, are accessible without restriction, and included in hiking and family touristic routes published by the administration responsible for its preservation and maintenance. The sites, analyzed here, were already published in documents of the administration and in scientific publications, so it was not considered that referring them would significantly increase their exposure to deterioration.
The problem with these sites is that, on the one hand, their geographical location and spatial configuration are not clearly defined in the available documentation, which makes it impossible for them to be properly managed by administrations. Secondly, a large part of the relevant scientific information on these sites is scattered, in analog format (in many cases), not classified, difficult to access, and does not have any maintenance, so it is susceptible to irretrievable loss.

The preservation of the results of paleontological research over time, (in order to guarantee access to knowledge for future researchers, developers of outreach products or the general public), is not only a priority that adapts to the European and Spanish regulations, but must also be considered as a moral duty. Preservation will allow that, even in the case of alteration or destruction of the fossil evidence, the information can still be studied. It should be noted that the future preservation and accessibility of the raw records, such as photographic collections, are of particular importance given the high vulnerability of the sites to be studied, a subject already addressed by several

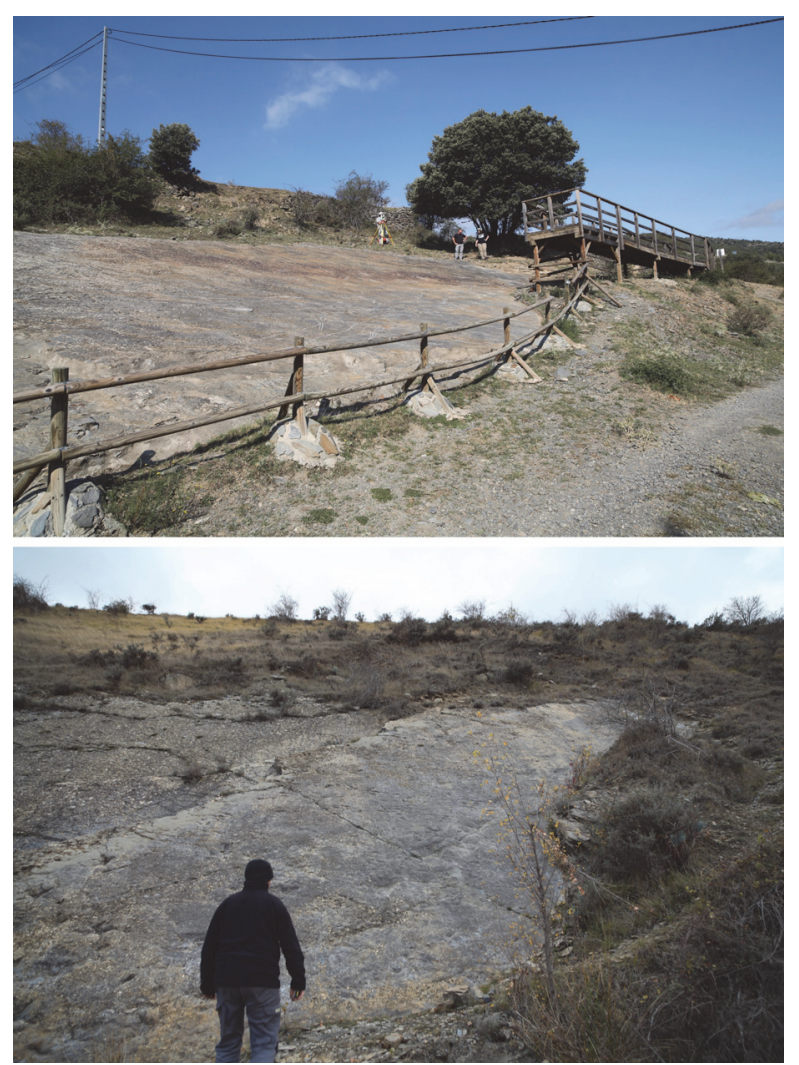

FIGURE 1. Two sites located in the municipality of Enciso (La Rioja). Above, "Virgen del Campo", below, "Icnitas-4". 
authors (García-Ortiz et al., 2014; Leal et al., 2016). In this regard, experiences are known in which, based on archival data, new cartographic products and 3D models have been generated, allowing us to recreate previous states of sites that have been degraded or disappeared several decades ago, thus being able to re-analyze them in their original state (Falkinghan et al., 2014; Lallensack et al., 2015).

The preservation of information is a complex problem, whose solution is not only to make data dumps. As has been repeatedly mentioned (Petruzzelli et al., 2011), there are deep problems of incompatibility of records and results between different production teams (apart from other difficulties derived from the lack of contextualization, scarcity of primary data sources, etc.), which greatly limit the interoperability between researchers and, ultimately, the re-use of paleontological information. In addition to guaranteeing the preservation of documentation, it is necessary to ensure access to it. This information must be operable in the future, understandable and credible. Therefore, it is necessary the development and application of a series of strategies and methodologies that range from design and selection of a metadata model, the application of controlled thesauri and vocabularies when making the descriptions, as well as the choice of the file formats in which the digital information will be stored and given access.

\section{MATERIALS AND METHODS}

The proposed action of this project is based on legislation and recommendations regarding the re-use of information (European Directive 2003/98/ EC, afterwards modified by Directive 2013/37/EU as well as its subsequent development in the Spanish legislation). It is related to initiatives such as the INSPIRE directive (Directive 2007/2/EC) for geographic data, which includes the sites under the theme "protected places" and which already has interesting examples of applications to heritage (McKeague et al., 2012) and geology (Janssen and Kuczerawy, 2012).

The research is located in an area of special paleontological interest (the municipality of Enciso in La Rioja, Spain). The first step was a search of the existing materials (published information such as scientific studies in journals and, essentially, unpublished information in the hands of researchers). With all of this and with the collaboration of the Cartography Service of the Government of La Rioja, a pilot computer project was developed through the IDE (Spatial Data Infrastructure) of La
Rioja (hereinafter: IDErioja). This project allows any user, freely, from any device connected to the Internet and intuitively, to access this information using an institutional web cartography server. Likewise, a methodology has been designed that makes it easier to continue incorporating the new data that is obtained, both from new research and recovered from studies already carried out, so as to advance towards an integrated system of paleontological information.

Figure 2 shows the general scheme of the proposal implemented by our work team. It is based on the information available to various researchers on a set of sites chosen by the criterion of being recognized and protected. On these sites the available information is studied, the one that is considered of interest for its publication is selected, and it is linked to its geographical position (previously revised). This information is prepared for its dissemination through the Cartography Service so users can access it. Likewise, the negotiation process between the agents is included in order to ensure the rights of reuse of the information that will be provided.

\section{DEVELOPMENT}

As indicated, this is a pilot project whose objective is to develop a data structure for paleontological heritage management through an SDI. Therefore, for the time being, it has not been included exhaustive information on all the sites; that is to say, so far we have introduced some examples that allow analyzing the use and potential of the proposal. Later, to the extent that both the administration and the rest of the potential users are able to use this resource and value it positively, it is expected to expand it with more information based on new work being done in the sites and the availability of means to recover information from the archive. In spite of this, it is also necessary to indicate that the web tool is operational and that it provides all its functionality for the available sites.

The information is grouped at the "site" level. In this regard, it was necessary to decide which sites would be introduced, at least in relation to their position and name in IDErioja. The bibliographic search revealed the existence of 32 paleontological sites located in the municipality of Enciso, as well as others that are known by neighbors but remain unpublished. Of all of them, they only have an official definition of position and name the 15 that were included in the BIC (Asset of Cultural Interest) declaration through Decree 34/2000. 


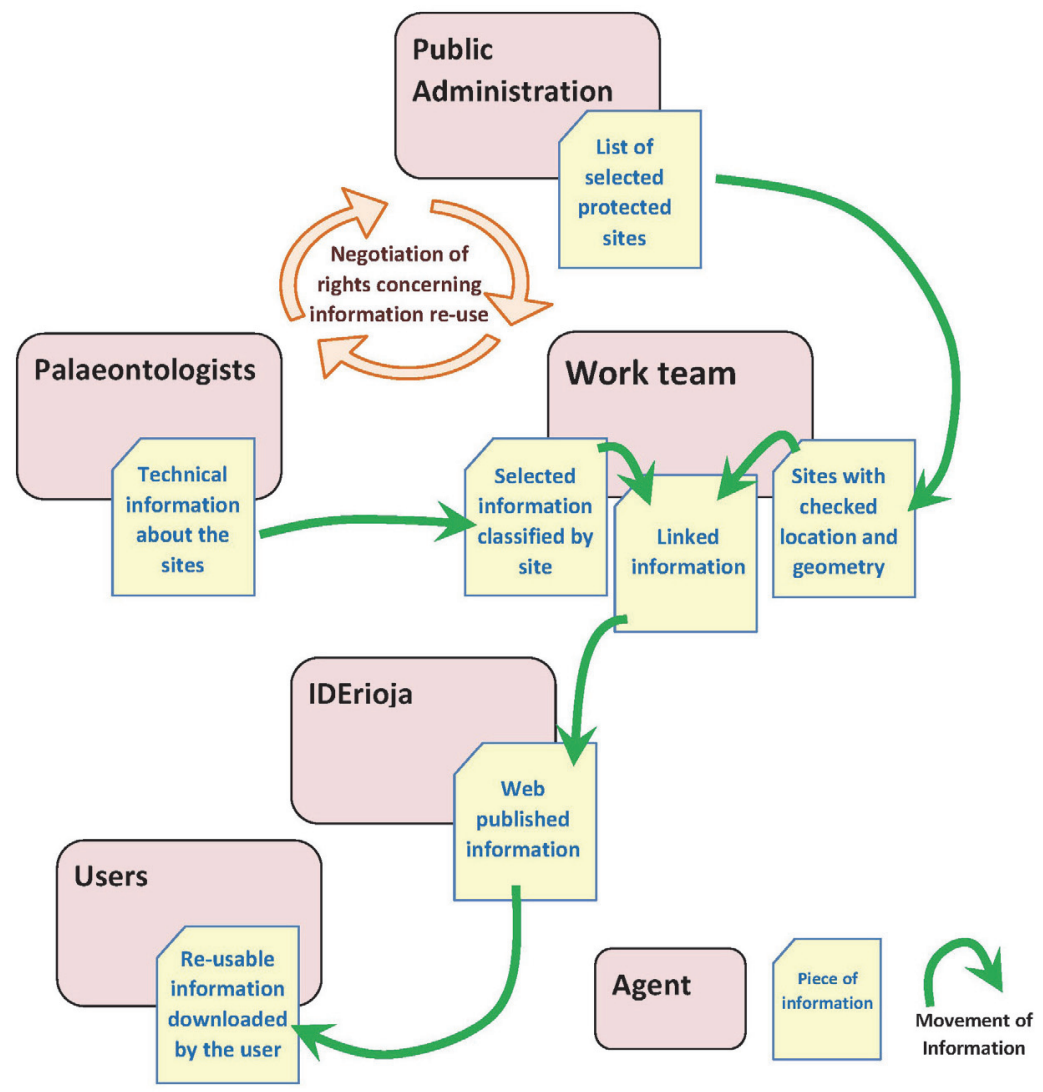

FIGURE 2. Scheme showing the agents involved in the work, the transformations and the movement of the information.

One of the fundamental tasks of this project has been to clarify the responsibilities and rights related to the information, as well as to provide the different actors with the legal coverage to use it. To this end, appropriate agreements have been established between the creators of the information, the physical depositories of the data (photographs, plans, etc.), those who have intervened in its processing (digitization, uploading to the servers) and the administration that offers the storage and access service through the SDI node.

Once the legal support was established, it was possible to attend to the technical design of the solution, which included the definition of the database, the selection of the information to be treated, the metadata schemas, the controlled vocabularies to be used, the characteristics of the copies that would be supplied (resolution, formats, types of use licenses, etc.).

Due to its special interest, among the different aspects of the technical design, we will now stop at some regarding the geographical location of the sites. Indeed, localization can be the cause of conflicts in any information management system, and even more so in the case of paleontology, in which the sites are part of the terrain itself. Also discussed is the specific case of the Valdecevillo site.

\section{Geolocation of the Sites}

Geographic location is essential within an SDI since it is the basis for representation and interoperability with other layers of geo-information such as the land registry maps, communication routes, protected spaces, etc. Therefore, the location must be obtained with the margins of precision and representativeness appropriate for the uses that are intended to be made. This issue is controversial since, in the absence of precise delimitations with official rank, each new author who studies the sites tends to create their own delimitations, which generates a state of arbitrariness and lack of coherence when locating the data. Also, some locations correspond to old works that were obtained for non-cartographic purposes, so it is not uncommon that the available coordinates indicate a place at a considerable distance from the site itself.

In view of this situation, the following criteria were adopted when defining the position of a site: 
- If available, use the positions that are officially published.

- In the case of multiple delimitations (sometimes in disagreement), indicate the position that best defines, within the cartography, the location of the sites and define what the criteria or scientific rationale is/are for making the change

- Maintain the traceability of the performed coordinate transformations (for example, conversion between reference systems and/or projections, passing the reference as a UTM grid to the definition as a perimeter, etc.).

- In any case, do include a note with the accuracy of the geo-location. Moreover, state the reference system and cartographic projection that are used.

Consequently, the collection of coordinates started from the BIC definition of the Enciso sites. Nowhere in the decree is the geodesic reference system used indicated, although, in the case of the year 2000, it might be understood that it will be the one used in the official cartography of both the National Geographic Institute and the Army Geographical Service by that date, that is, the denominated as ED50 (European Datum 1950). At present, the current reference system is the one named as ETRS89 (European Terrestrial Reference System 1989), and it is this one in which the official cartography is referred and, therefore, the one that uses the Spatial Data Infrastructure of La Rioja (IDErioja) in which the results of this work were deposited. For this reason, it was necessary to carry out the transformations between both systems (the difference in this area is about $200 \mathrm{~m}$ ).

Another problem is that the sites are superficial entities but the official definition that appears in the BIC statement only provides their position through a point. To solve this discrepancy, in all the sites, except in Valdecevillo as will be seen later, polygons have been generated in the form of a square of $4 \mathrm{~m}^{2}(2 \times 2 \mathrm{~m})$ centered on the previously calculated point. Of course, these polygons do not represent the site correctly, but at least allow it to be included in the database as polygon entities and incorporate the related information. When, in the future, the official geometry corresponding to the polygon is available, it will only be necessary to update the geometry of the database while keeping the rest of the information. Obviously, this way of proceeding must be complemented with an attribute that is associated with each perimeter and that indicates to the user what is its validity, that is, according to what criteria this perimeter has been determined and what legal support it has.
Of course, the representation as polygons does not prevent, in a complementary way, also having identification in the form of a point. For example, this one can be used to place an icon in the small scale visualizations. In order to verify the positional accuracy of these polygons, the differences with respect to the actual position of the paleontological remains have been analyzed on cartography with discrepancies of up to $50 \mathrm{~m}$ being detected. It is clear that the coordinates that were defined for the BIC declaration are not suitable for inclusion in the IDErioja geographic databases, given that they do not define the sites with sufficient precision or detail. As a result, they do not allow exploiting the potential of geographic management, that is, inquiries such as in which cadastral plot a determined site is located or at what distance from a certain road. However, despite all these deficiencies, these coordinates are the only ones that have some type of official recognition and, therefore, the only ones that should be integrated into the database of the Government of La Rioja. Otherwise, we would be operating with geometric entities that have no meaning for legal purposes, which would cause multiple problems when performing management tasks. The solution to this situation would be for the Government of La Rioja to promote a new work to delimit the sites and to give them legal validity through the corresponding update of the BIC declaration. Obviously, this revision of the perimeters should be obtained under the advice of technicians in paleontology that would establish the zones to be protected, which should include both the surfaces in which there are visible remains and the areas of presumption that, equally, deserve to be taken into consideration. In any case, regardless of how the site perimeters are defined, it must be borne in mind that the defining geometries of the sites must indicate the procedure followed to obtain them, the reference system used, the precisions achieved, and the technical cartographic criteria that guarantee their traceability and define the quality of the geographic data. However, while awaiting for this new definition of perimeters to exist, it is necessary that the management system begins to function and, for this, despite its defects, it is necessary to rely on the coordinates of the BIC declaration of the year 2000.

\section{Geographic Names}

The location of a geographical element can be done both quantitatively by identifying with coordinates in a given system and by means of topon- 


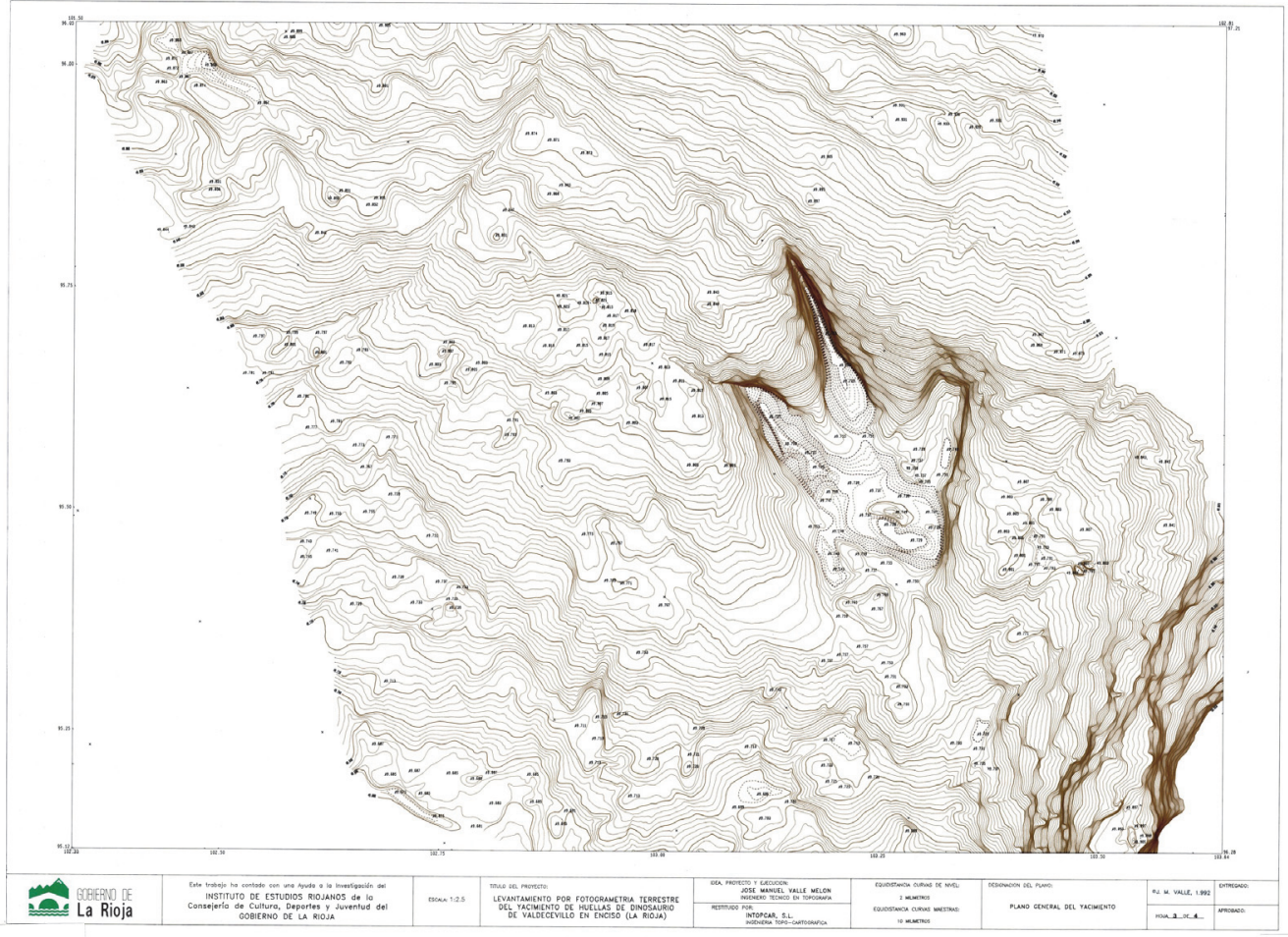

FIGURE 3. Photogrammetric survey of one of the tracks (scale 1:2.5). Initially published in Valle (1993) in black and white. The version presented here is in color, offers more detail, and retains the metric (since it is obtained from the original CAD file while the copy of the article was a photocopy).

ymy. Geographical names can refer to locations that are extremely local or as wide as a continent. As was done with the coordinates of the sites under study, the quality of the toponymical definition of the same was analyzed, for which both the official gazetteers and the cartographic series of the National Geographic Institute and the Geographical Service of the Army and publications on local toponymy. In this aspect we must indicate that there are two erroneous place names in the BIC declaration that, in the present work, have been corrected, since their confusion has been dragging along the successive publications that cite them, and it was considered that maintaining the error only contributes to its persistence.

\section{Valdecevillo Paleontological Site}

The Valdecevillo site is one that was first studied in La Rioja and on which more research work of different types has been developed (Casanovas and Santafe, 1974; Casanovas et al., 1989; Valle, 1993; Díaz-Martinez et al., 2010). For this reason it has been chosen to carry out an exhaustive dump of the existing information about it, thus serving as a test of implementation and example of the potential of the generated product. With respect to its geographical definition, instead of the $2 \times 2 \mathrm{~m}$ chart that was obtained from the definition of the BIC, a perimeter obtained in the field by GNSS observations has been used and serves as an example of how these definitions would be once it is decided to update those corresponding to each site .

The information available on this site includes sketches of the excavations, plans, slides, and reports, as well as other documents of very different types, such as brochures, tourist guides, postcards, and newspaper articles. All these materials have been digitized and incorporated into the archive (Figures 3-4).

The digital files have been enriched by the incorporation of metadata so that regardless of where they are located and how they are subsequently redistributed, they have information about their content, authorship, rights, and purpose of their creation. The schemes used depend on the type of file, for example, a combination of Exif and IPTC for photographs or Dublin Core for text documents and plans. If internal metadata are not included in each document, there is a risk of reproducing the same problems that have been found in many of the analog images (paper, slides, etc.) that have been located among the documentation pro- 


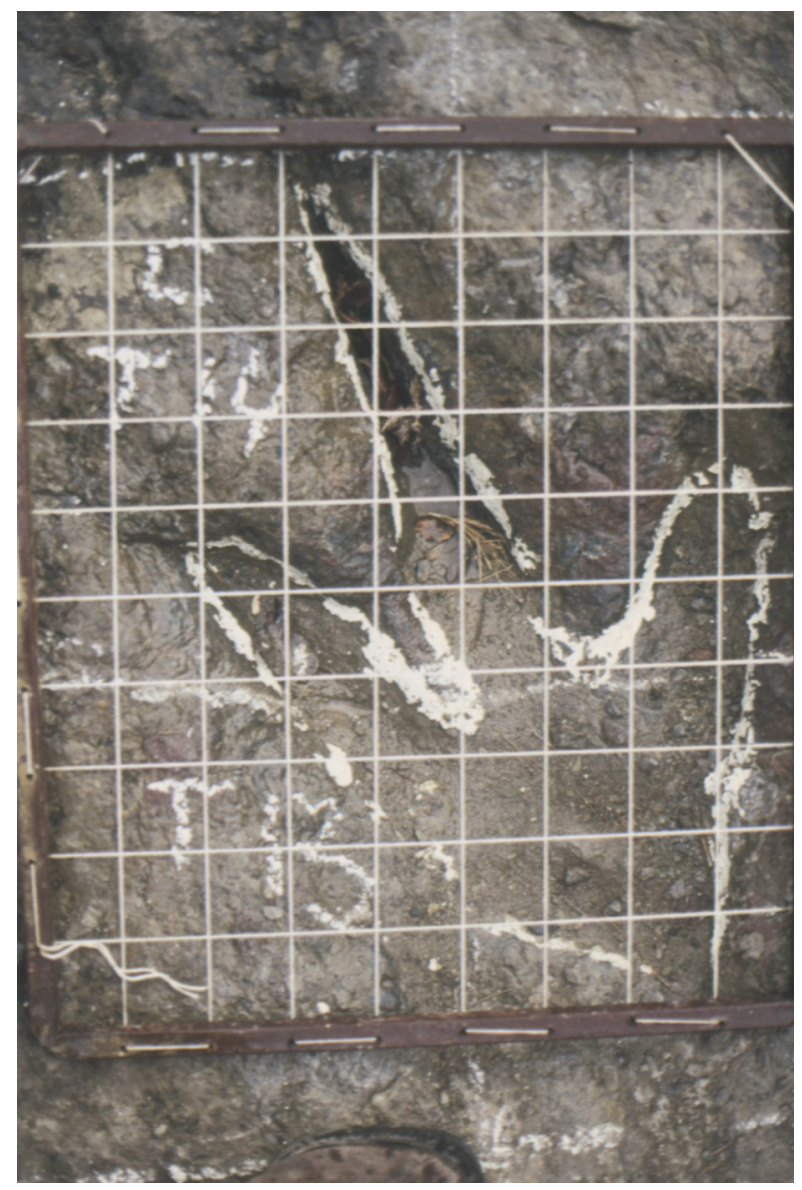

FIGURE 4. Same footprint of the previous figure, as recorded during its excavation in 1984. Image obtained by digitizing the slide film (analog format).

cessed for this project but that, having no reference to their context, they have had to be discarded, given that it was impossible to know what they are referring to and what they can be used for in the future.

On the other hand, the paleontology layer that is available through IDErioja has metadata according to the ISO 19115 scheme, which allows incorporating general project information. In addition, this scheme has some particular characteristics that make it particularly suitable for describing geographic information. In particular, this scheme requires that the reference and coordinate systems used are indicated (thus eliminating the cases of ambiguity as the aforementioned between the ED50 and ETRS89 systems). Also, it incorporates indicators of data quality (such as geometric precision) and a description of the sequence of processes that have been carried out during the processing of the information. In this way, the user

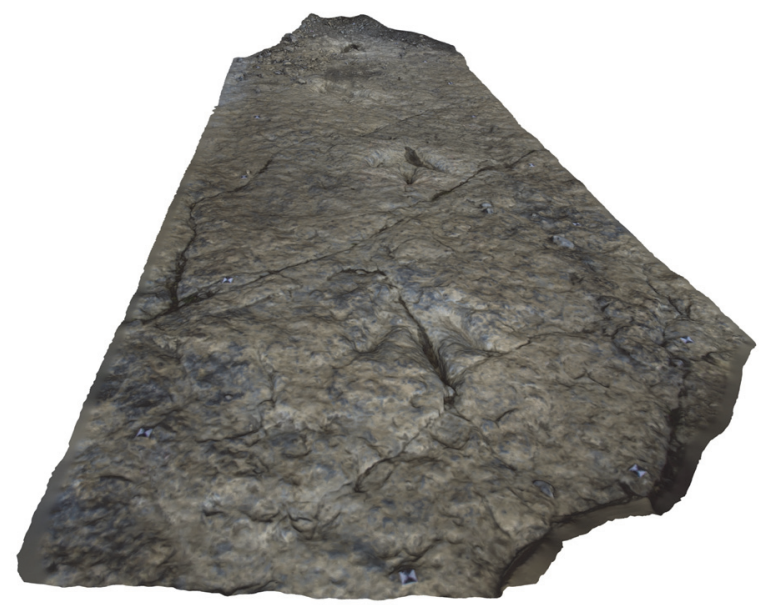

FIGURE 5. Interactive virtual model of one of the trackways of the Valdecevillo site generated by photogrammetry. Perspective view of a track with an approximate size of $1 \mathrm{~m}$ with by $4 \mathrm{~m}$ long.

knows the traceability of the data (called "lineage" in the terminology of ISO 19115).

Since the sites are part of the territory, they undergo changes due to anthropic and natural actions. In addition, these are study areas that change as the excavations are extended, restoration or musealization actions are undertaken, new analyses are carried out with new techniques, etc. Therefore, it is interesting to consider that the database can incorporate new information from the sites over time and that this fact allows analyzing and managing them taking into account their temporal evolution. In the case of the Valdecevillo site, new products have been generated that reflect its current state, specifically, a three-dimensional model obtained by photogrammetric methods (Figure 5) and a video taken from a drone (Figure 6).

\section{RESULTS}

The design of the specific database for paleontology was made from the previous databases of the Ministry of Culture and in collaboration with the staff of the Geographical Information Systems and Cartography Section of the Government of La Rioja (IDErioja) for the aspects of implementation. The first decision to be made was to define what would be the unit of action for the management of paleontological information, since information on sites, trackways, and footprints is available. Precisely, each one of them responds to a spatial typology that can be collected in the IDE, so the sites can be considered superficial elements, the 


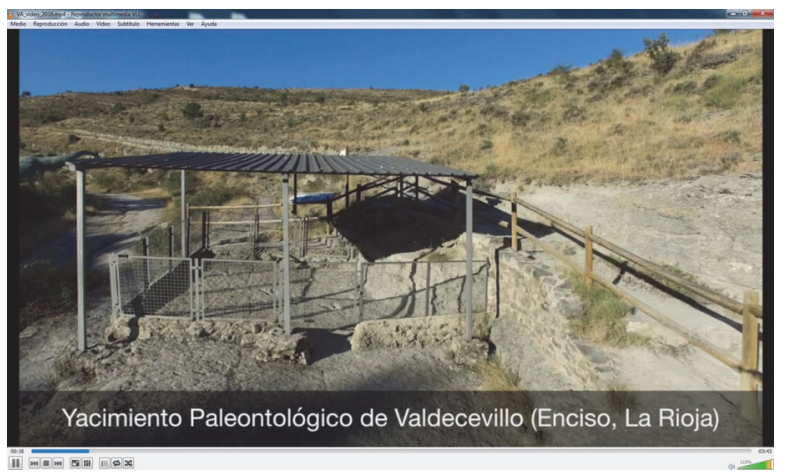

FIGURE 6. Video obtained with a drone in which a flight is made through the site.

traces linear elements, and the traces punctual ones.

During the first weeks, the advantages of each one of them were analyzed and even the possibility of the combination of the three types. It was finally agreed that the best option consisted of grouping at the site level, but coding the name of each document associated so as to maintain traceability in terms of footprint and trackway, since this information is collected for each of the ichnites. The design was contrasted with IDErioja to verify its viability. Some adjustments and improvements were made, consisting in the non-implementation of some fields, adding characters to others and suppressing the obligatory nature of the inclusion of information in those fields for which said information was not always available. The generated layer is accessible within the IDErioja catalogue. It also has a specific thematic viewer that only shows this information on the base cartography or the updated orthoimage (Figure 7). This viewer can be consulted on any device with Internet access, either in the office or on mobile devices (in which case, the possibility of geolocation on the map is offered so that it can be used as a guide for the visit). The screen shows an interactive map with the location of the sites, in addition, it allows the download of the information (vector elements and associated attributes), as well as the realization of searches by site, municipality, or value consigned in the attributes. Once a site has been selected, its attributes are displayed (code, name, description, geological age, lithology, protection, type of access, signage, bibliography, etc.), as well as access to associated documents and photographs.

On the other hand, the following OGC (Open Geospatial Consortium) standard services have been created for the search of maps (WMS - Web Map Service - https://www.opengeospatial.org/

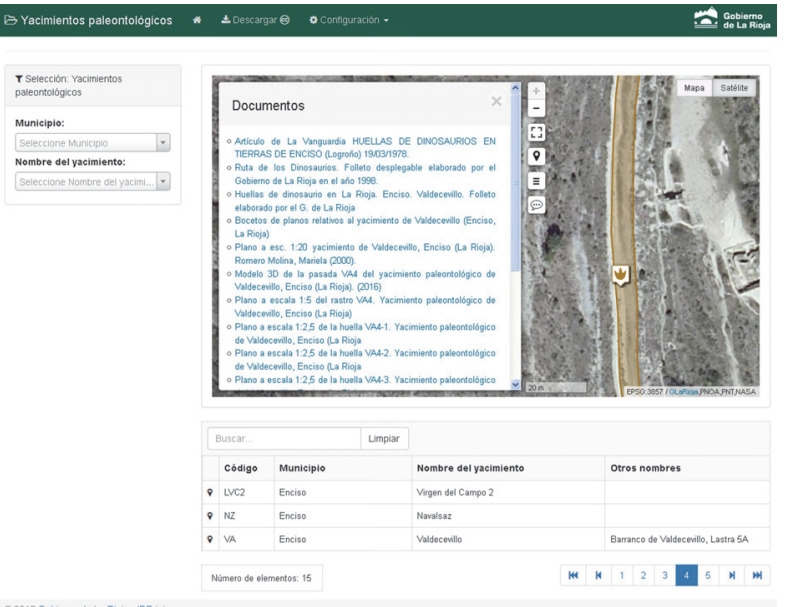

FIGURE 7. Interactive thematic map with paleontological information, available on the web cartography server of the Government of La Rioja (https://www.iderioja.larioja.org/vct/

index.php?c=3373703472624e584d383336386433616 7334f6b64513d3d\&t=3.

standards/wms) and for the download of entities (WFS - Web Feature Service - https://www.opengeospatial.org/standards/wfs).

These services are accessible directly through a web browser. Also, most GIS and geographic viewers (such as Google Earth $囚$ ) allow transparent linking to the user and the visualization of their content together with other layers of information that are either linked to other OGC services or locally available (for example, in SHP-shape files) (Figure 8).

\section{CONCLUSIONS}

The public availability of abundant, adequately contextualized and quality information on paleontological sites for researchers, the administration and the public in general will not only allow their valorization but also the promotion of new social and economic activities. However, at the present time, this information is scattered, in many cases, within the personal files of the researchers themselves and in analog formats (paper, slides, carbon copies, etc.) that are not digitally adapted to outreach standards.

All this prevents, to a large extent, their exploitation, and increases the risk of loss of information in a short period of time. By providing this information via the Internet through the Cartography Service of the Government of La Rioja, it is possible to place it in its spatial context, since it is directly integrated with the rest of the available data for the province (relief, hydrography, trans- 


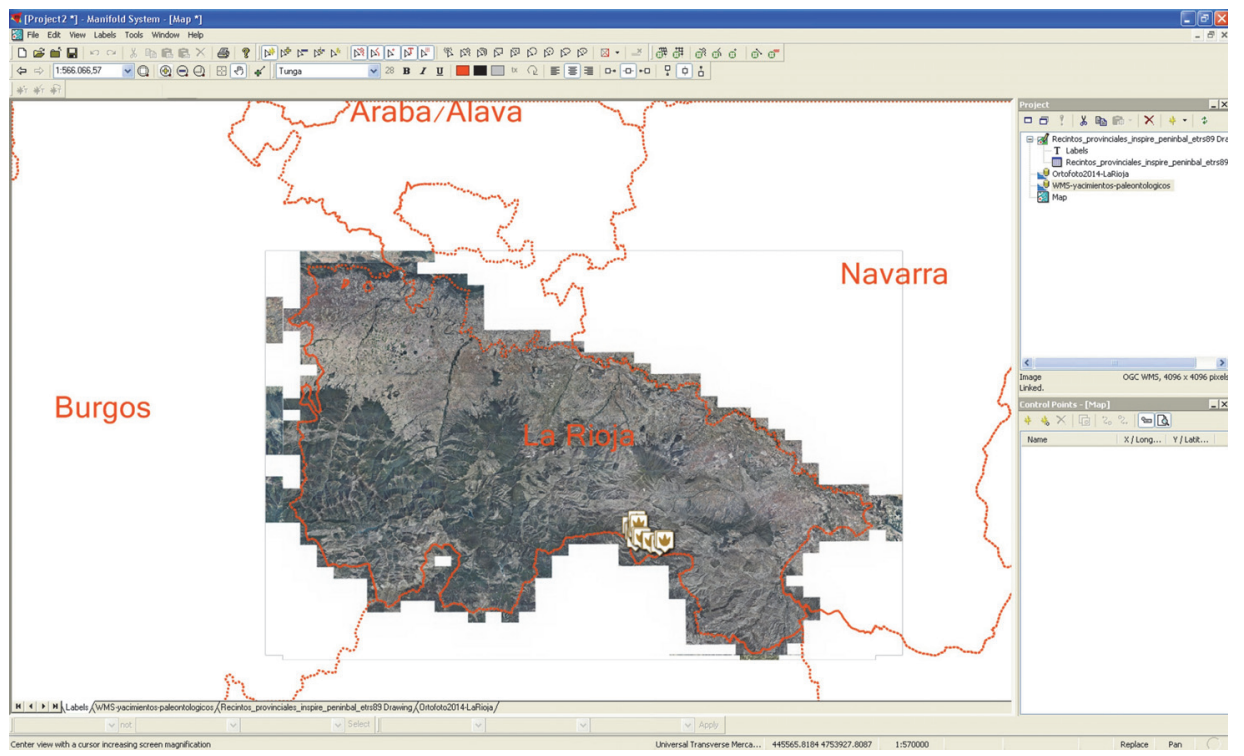

FIGURE 8. GIS environment in which the paleontological information is linked to the orthoimage of La Rioja (both as WMS services). Information is visualized together with a vector file (SHP format) with the perimeters of the Spanish provinces.

port, urban centers, natural resources, etc.). In addition, it opens the possibility of using this information from mobile devices so it can be used for the creation of tourist and cultural routes and products that allows society to connect with this extraordinary paleontological heritage. However, the declarations of Asset of Cultural Interest of the sites subject to management and protection need to be updated. This update needs to address especially its geometric definition. In fact, given the current context of geospatial information it is completely inappropriate that the definition of paleontological sites still corresponds to point entities, defined in ambiguous coordinate systems and with uncertainties of several tens of meters. As a result, a proposal for the management of paleontological heritage information of La Rioja from the regional SDI is offered. The approach develops in detail a pilot site (Valdecevillo) and, more generally, all the sites of the municipality of Enciso that are declared as BIC. The generated web application, at the present time, is being analyzed by different types of users in order to contrast its usefulness and point out the possible modifications to be introduced.

\section{ACKNOWLEDGMENTS}

This work had the support of the Institute of Rioja Studies (Government of La Rioja) through the 2015 grant "Research Projects of Rioja Thematic". Likewise, we would like to thank the IDErioja staff for their collaboration and excellent disposition, in particular, G. López García, and E. Pascual Pinedo.

\section{REFERENCES}

Casanovas, M.L., Fernández, A., Pérez-Lorente, F., and Santafé, J.V. 1989. Huellas de dinosaurios de La Rioja. Yacimientos de la Virgen del Campo, La Senoba y Valdecevillo. Instituto Estudios Riojanos de Ciencias de la Tierra (12).

Casanovas, M. L. and Santafé, J.V. 1974. Dos nuevos yacimientos de icnitas de Dinosaurios. Acta Geológica Hispánica, 9(3):88-91.

Díaz-Martínez, I., de Landaluce, E.G.O., Lorente, F.P., Sáinz, A.M.C., and Vela, A.J. 2010. Virgen del Campo, La Senoba y Barranco de Valdecevillo: tras las huellas de los dinosaurios de Enciso. Cidaris, 30:339-347. 
Falkingham, P.L., Bates, K.T., and Farlow, J.O. 2014. Historical photogrammetry: Bird's Paluxy River dinosaur chase sequence digitally reconstructed as it was prior to excavation 70 years ago. PLoS One, 9:e93247. https://doi.org/10.1371/journal.pone.0093247

García-Ortiz, E., Fuertes-Gutiérrez, I. and Fernández-Martínez, E., 2014. Concepts and terminology for the risk of degradation of geological heritage sites: fragility and natural vulnerability, a case study. Proceedings of the Geologists' Association, 125:463-479. https:// doi.org/10.1016/j.pgeola.2014.06.003

Janssen, K. and Kuczerawy, A. 2012. Increasing the availability of spatial data held by public sector bodies: some experiences and guidelines from the OneGeology-Europe Project. IJSDIR, 7:249-276.

Lallensack, J.N., Sander, P.M., Knötschke, N., and Wings, O., 2015. Dinosaur tracks from the Langenberg Quarry (Late Jurassic, Germany) reconstructed with historical photogrammetry: evidence for large theropods soon after insular dwarfism. Palaeontologia Electronica, 18:134. https://doi.org/10.26879/529

Leal, A.S., Dionisio, A., Sequeira Braga, M.A., and Mateus, O., 2016. The long term preservation of Late Jurassic sandstone dinosaur footprints in a museum environment. International Journal of Conservation Science, 7.

McKeague, P., Corns, A., and Shaw, R. 2012. Developing a spatial data infrastructure for archaeological and built heritage. IJSDIR, 7:38-65.

Pérez-Lorente, F. 2017. Developments and contributions in the study of La Rioja dinosaur footprints (Spain). Spanish Journal of Palaeontology, 32:171-184.

Petruzzelli, M., Razzolini, N., and Francescangeli, R. 2011. Proposal for an uniform data standard for ichnological 3D tracking and post-processing. Rivista Italiana di Paleontologia e Stratigrafia (Research in Paleontology and Stratigraphy), 117.

Valle, J.M., 1993. Metodología y resultado del levantamiento por fotogrametría terrestre del yacimiento de huellas de dinosaurio de Valdecevillo en Encisco (La Rioja). Zubía, 165-186. 